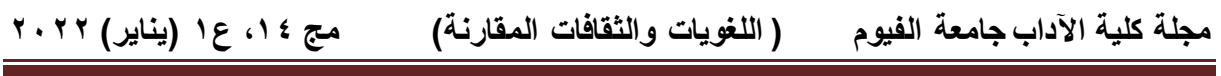

\title{
THE ECOLOGICAL FUNCTION IN MIKE BARTLETT'S EARTHQUAKES IN LONDON
}

\author{
Ruwayda Gaber* \\ ruwayda.gaber@yahoo.com
}

\begin{abstract}
:
Since the main interest of ecocriticism is to focus on the strong bond between literature and Nature generally, and environment particularly; it is good to use an Ecocritic approach for analyzing Earthquakes in London by Mike Bartlett. This play that was first introduced in London in 2010 tells the story of a family that consists of four members: a father who is introduced as an environmentalist and his three daughters. Every one of them has a certain problem that spoils her ease. Their sufferings are closely related to both climatic and ecological rapid changes. Thus, this paper will try to discuss through this play how ecology expresses both natural and constructed elements. It also will discuss the representation of environment through this play showing how Bartlett manipulates both stage and language to give a full representation of ecology and makes an attractive ecological atmosphere. It also will shed ample light on the relation between Man and environment through the variant relations between the characters in this play and the environment around them. One of the most important points in this paper will be the exposure of the mutual apocalyptic influences of Man's misuse of the environment. Finally, this paper will rely on The Future of Environmental Criticism: Environmental Crisis and Literary Imagination by Lawrence Bull as a base of standing on the ecological functions in Earthquakes in London.
\end{abstract}

Keywords: Eco criticism- Setting- Second- wave ecocriticismEnvironmental justice

\footnotetext{
Lecturer of Comparative Literature - The Higher Institute of Artistic Criticism - Academy of Arts.
} 


\section{Introduction}

Earthquakes in London is a modern play that" examines how life is lived under the threat of climate change and impending catastrophe"[Taylor 2].This play discusses the issues of global warming and earthquakes showing their influences on people within a social frame. So this play can be analyzed from the perspective of ecocriticism, especially as Howarth defines ecocriticism as:" a name that implies more ecological literacy"[69]. The play under study tells the story of Robert who is an over sixty environmentalist. He is a father of three daughters. His relation to his daughters is troubled. Robert thinks that he can stop the growing global warming; sometimes he speaks in a way that makes the play" (mix of zeitgeist-capturing ambition and irreverent refusal to lapse into tidy-minded preaching [Taylor 5]". After years of disputes with his daughters, he communicates with them again warning them against the expected climatic changes. However, they pay his warnings no attention. Every one of them has her own life, ambitions, and personal problems. This troubled familial relation between the members of the whole family is impressive, because it makes the atmosphere proper for shedding light on the dangers of the climatic changes showing the bullying actions of people towards nature.

Bartlett seems to be influenced by his childhood experience of bullying; he says that as a child he had" a pretty horrible experience of bullying" and admits that" he sees himself in all the characters he writes" (6). Hence, his characters in the play under study live in a case of

(THE ECOLOGICAL FUNCTION...)Dr. Ruwayda Gaber 
uncertainty and troubled relations with each other. So it is acceptable from them to deal with environment in such an offensive way and to pay no interest in the warnings of Robert. Furthermore, this reflects the case of uncertainty which all of them lives in and this enhances "the idea of certain fate of life on earth"( Bull 1). This case of uncertainty on their part makes them not really aware of the dangers of the climatic changes that endanger the Earth. So an audience can realize the deterioration of the environment and expect the troubled future of these characters. Hence, the audience becomes part and parcel of what is introduced before them on the stage. This widens the scope of the importance of this play as an ecological drama. Accordingly, it is important to discuss the concept of eccriticism within this play.

\section{Ecocriticism}

As Cheryll Glotfelty believes that Ecocriticism mainly" seeks to evaluate texts and ideas in terms of their coherence and usefulness responses to environmental crisis", it is acceptable to discuss the ecological function in Bartlett's Earthquakes in London[4]. This play shows clearly the effects of these apocalyptic climatic changes on the lives of the characters in the play. So the environmental issue is professionally interwoven within the play under study. This achieves what Lawrence Bull comments on saying:"

The environmental turn in literary studies has been more issue- driven than method or paradigm- driven is one reason why catchy but 
totalizing rubric of "ecocriticism" is less indicative than environmental criticism or literary- environmental studies... and all the more so now that environmental criticism's working conception of" environment" has broadened in recent years from" natural" to include also the urban, the interweave of' built" and" natural" dimensions in every locale, and the interpretation of the local by the global[11$12]$.

Earthquakes in London is a play that centers on the dangers of the recent climatic changes and their reflections not only on the present generations but also on the new coming ones. So it is good to apply the ecocritical approach to this dramatic text, particularly because" the main premise of Ecocriticism is to study the relation between environment and Nature.'(xxi). The main problem in this play is the problems of global warming and the expected apocalyptic earthquakes that will attack London; "Freya This is what I was trying to tell you. They said there's going to be an earthquake" [21]. Freya's words announce the main idea of the play and showing the cause of horror and worry that over controls her.

\section{Second- Wave Ecocriticism}

The issues of global warming and earthquakes are discussed from a social perspective not from a pure natural perspective in Earthquakes in London. So it is proper to classify this play as a play that employs the perspective of 
second- wave ecocriticism that studies environmental issues in literature from urban and social frame. Bull argues:" Second-wave ecocritics tended to focus on urban spaces and environmental justice. He thus argues that the second wave is "Sciocentric" while the first wave is ecocentric"[94]. Hence, the issue of the climatic changes is shown from the perspectives of the ordinary characters within the play. For instance, Jasmine, the teen ager daughter of Robert, describes herself as" a natural fucking disaster" [19]. Such a troubled character represents the dangers of violating nature and the misuse of environment. This agrees with what Julie Rivkin and Michael Rayan believes that" the second wave ecocriticism owed more to social ecology"[12-15]. So people's reaction against this problem is very important because as Bull confirms:" like racism, environmental crisis is a broadly cultural issue not the poetry of a single discipline"[1]. This play exposes people's underestimation of the importance of the climatic changes. Sarah is a good example of such underestimation.

Sarah, the oldest daughter of Robert and a supreme politician in a coalition government, is interested in stopping the new expansions of the Heathrow Airport. She focuses on the economic results only. Environment is not among her own interests. She as a politician fails to put an end to the misuse of environment. All her function is to think in the economic and sustainable development. This what Bull defines as" ecological modernization" but with its narrow meaning [ 17]. For her, finding a solution for the problem 'is complicated, because we have to consider everything. 
Transport means investment. Investment means greater employment. Greater employment means less poverty, which I assume you're in favor of?' [ 54]. This confirms the crisis; the environmental crisis on Earth. That is not only a capitalist crisis but an intellectual and cultural crisis: the absence of imagination that is commented by Lawrence Bull as" a crisis of the imagination, the amelioration of which depends on finding better ways of imaging Nature and humanity's relation to it'[2]. There is no a little bit of finding a solution for the environmental crisis on her part as a politician. This expresses the atmosphere of confusion, despair, frustration and loss of hope that prevails throughout the play.

According to Fredric Jameson" It seems to be easier for us today to imagine the thorough going deterioration of Earth and of Nature than the breakdown of late capitalism."(xii). All characters in this play deal with the crisis of climatic changes from different perspectives. However, none of them offers a solution for it. Instead, they express confusion whether on the familial level or the public level. Chris Joe comments on this:" Earthquakes in London identify a notuncommon familial situation; you can despise, and be hurt by, those with whom you agree politically, and that does not help us make collective change"[27]. This is exactly the case within Robert's Family.

The relations between the three sisters, Sarah, Freya, Jasmine, their father Robert, and Steve the husband of Freya are troubled as well as their relation to their father. When Colin, the lover of Jasmine, tries to blackmail Sarah, she gives him hell. Even Jasmine makes a love affair with him to 


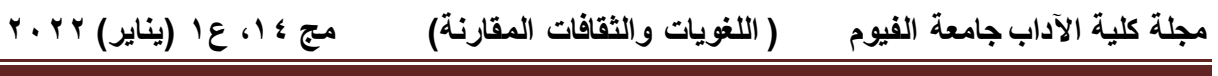

put her sister Sarah in critical situation and so on. Although this play focuses on the climatic issue, there are other issues that can be discussed in. According to Kerstin Bookman:" Earthquakes in London asks a different question: How will drastically altered weather make us all feel and how it will change? How we treat those we love?'[28]. This proves at first the direct influence of the climatic changes on Man. Second it confirms the strong bond between man and Mother Nature. This what Bull calls as" The second wave of ecocriticism"[22]. It focuses on the social relation between Nature and the social atmosphere around it. For Bull:" It takes urban landscape as seriously as natural landscape... It seeks to locate the vestiges of nature in cities and exposes crimes of eco- injustice against society's marginal section"[ 24-5]. Thus it is of importance to discuss environmental justice.

\section{Environmental Justice:}

Environmental justice is a term coined by ecocritics. It means that all people should share benefit from nature. All people should enjoy nature.[ Amaladass 90] accordingly the misuse of nature by some people will last to affect all people even the next coming generations.

Robert: These excretions, from all of these creatures, they go up into the atmosphere, and you can imagine globally they would make quite a difference to its composition. So it follows that if we could accurately measure the composition of gases in the 
atmosphere of a planet like Mars, we could tell whether there was life [14].

It shows that everyone is responsible for the deterioration of nature and already for the climatic change. This is showed clearly in the play through the following dialogue:" Grace: So all the time, every bit of life, animals, humans, everything, Change the environment. Robert: Yes. You are right now. The room is entirely different because you're in it" [14]. All creatures on Earth suffer from the climatic changes. No one can escape. To confirm this, Bartlett introduces a big number of characters. This is very effective.

Bartlett introduces various characters of different ages so as he could introduce a comprehensive image of the influences of the climatic changes on people through different periods of time. He introduces Robert the over sixty environmentalist as well as both Sarah and Freya who are thirties. He also introduces Jasmine the nineteen teen with all her contradictions. Also the audience meets The Old woman and her husband. He also introduces various sectors of society including supermarket man, passersby $1 \& 2$. This gives more comprehensiveness to his ideas that are various and multiple. For Michael Billington" Now he- Mike Bartlett- has written a big, epic, expansive play about climate change, corporate corruption, fathers and children". It shows that all people are responsible for the climatic deterioration and they are also the direct victims of such changes. All matters go worse than it was in the past and they will be worse in the future than they are at present. The following quotation shows this: 


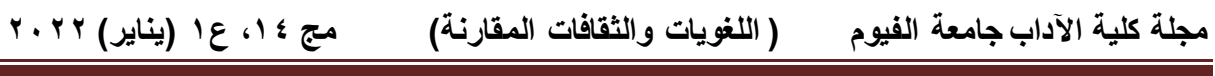

S. Worker: Vegetables and shit are over there.

Colin: I'm sorry?

S. Worker: Vegetables and fruit and all that are over there.

Colin: I know but I've looked and I can't find it.

S. Worker: Probably don't have it then.

Colin: Probably.

S. Worker: Yeah.

Colin: Can you check?

S. Worker: Chhh[52].

It shows how the new climatic changes have affected agriculture. The Climate is not proper to plant fruits. Something dangerous occurs. Everything begins to fade away. Every one suffers a lot. The theme of suffering is very clear in this play.

The idea of suffering is professionally introduced in this play; it is introduced in a way that confirms the necessary bond between Man and environment. The Earthquakes in this play are connotative. The play runs around the idea of expected Earthquakes in London. This is one aspect, while the other is a psychological aspect. The new climatic changes in London have a direct influence on Londoners themselves. So they cannot enjoy the modern life. The following dialogue between Freya and the Old Woman shows this: 
Old Woman: That was our England. All gone now of course. Things move so fast. The cars, the internet. Yes we had children, but I never see them. Always got something better to do. So instead, I come to the heath. And wait.

Freya: What for?

Old Woman: The silver lining. Soon it'll all be over.

Freya: I'm looking I'm really looking for something good, happening now, but you're saying things are only getting worse.

\section{Old Woman: Religious} intolerance, economic collapse, tsunamis, riots ... it's the perfect conditions.

Freya I don't understand.

Old Woman: Is it a boy?

Freya: A girl.

Old Woman: A little girl. Well. I hope she can fight. The problem of getting children in such a chaotic world where everything represent ill omens. 
The Old Woman is worried about the future of the expected daughter of Freya. This is very important, because it proves that the problem is continuous and matters will go worse than it is now. It shows how the Londoners yearn for past England; the past pastoral London where everything was in a green dress, and air was fresh. So there is a dire need for reconciliation to protect London. Hence, there is a dire need for reconciliation.

The idea of reconciliation can be applied to the members of Robert's family. After years of dissonance with Robert and his daughters, he communicates again with them. He tries to warn them against the expected apocalyptic earthquakes that endanger London. However, his reconciliation with his daughters does not bear its fruit. $\mathrm{He}$ imagines that he can save the planet. This reconciliation after years of contentions confirms the social bond between Man and Nature in general. For Billignton In Earthquakes in London:" what we witness is both a partial family reconciliation and an acceptance of the need for positive action to save the planet"[20]. It shows how Man is directly responsible for the damage of the planet. How Man destroys his life, when he destroys the planet. So the expected seismic actions in Earthquakes in London are nothing but the angry response of Nature to the Londoners modes of life that does not appreciate the ecological nature of their country ( London). Hence, what occurs in London occurs in other places. So the idea can generalized to contain the whole planet. Charles Spencer argues:" the nub of Bartlett's play is that disaster may overwhelm planet Earth long before then and the shows mood of febrile anxiety about global warming

(THE ECOLOGICAL FUNCTION...)Dr. Ruwayda Gaber 
at times succeeded in niggling even a crusty climate- change septic like myself'. So the problem of climatic changes is continuous.

The problem develops with the passage of time. It is never solved. That is because man's modes of life are ecologically apocalyptic. So the play introduces the problem through different periods of time. Hence Nature still faces the same damage during the life circle of people. The following quotation is very important:

Grace: When you fell in the river, Freya, you hit your head. You did some damage. And sometimes, when that happens, people become unable to see a distinction between their own particles and those around them. They can't see the edges of their body anymore where they stop and the world begins. They can instead understand instinctively that we are all just different recycled pieces of a larger, older creature. We are simply earthquakes ourselves, wonderful irregularities in an evolving system. We die and the earth uses us for something new.

Young Robert enters, dressed in white, and wheels in a cot. 
Yes Freya, this is the future, and I am your mother. But this is also the past and the present, and I am your father, your sisters, your friends, your husband, the table, the bed, the ground, we are Everyone that is, was, and everything that will be. I'm nature all in one. So are you.

Freya: This isn't real [136].

Freya is a representation of the Mother Nature with all its contradictions, sufferings, pleasures, and hope for change. Mother Nature suffers a lot. However, no one pays it a little bit of attention. Nature is an organism that deserves more interest and appreciation as well as collective work.

Saving ecology requires a collective work, because all organisms on Earth face the same apocalyptic influences of the misuse of environment. So it is noted that sometimes more than one character are involved in one scene; the scene in the swimming pond contains Freya, the old Women, Jasmine, and other women with their babies. This is very suggestive, because it shows how Freya feels afraid of bringing a baby in such an apocalyptic world. The scene ends with the women encircling her raising their babies. So the expected dangers will affect both Freya's expected baby as well as other babies. Moreover, the characters in this play notice very well the results of the misuse of the environment. From time to time, there is a reference to their sufferings in their country. Sarah says:" Department of climate change, massive office and nothings green. It's ridiculous...Flowers 
are dead. We want some life around here"[17]. Characters with different ages have the same suffering. So all characters should work here for saving London and making it better than it is but not to misuse or destroy it. Tom King argues:" So all the time, every bit of life, animal, humans, everything change the environment"[ 14]. It means that everything on Earth has a role in protecting and saving ecology. Thus introducing a well-designed stage that is pregnant with many characters is to the credit of this play; the play seems to be an epic.

\section{Setting}

Earthquakes in London is an epic play. Bartlett controls the stage very well. This play deals with an ecological issue through packaging events in a family story. The play is a scenery play. This keeps the epic atmosphere of the play. Hence, he introduces a big number of characters representing different sectors in society. Aleks Sierz comments on this:" Mike Bartlett's new play is a thrilling epic account of climate change". Dealing with the issue of ecology is very important for all people in spite of sex, religion, and even color of complexion as well as culture. Because it is a universal issue that should be discussed from various points of view. Accordingly the stage should be rich in different types of characters and well designed. Bartlett comments on this saying:" I knew that if it was going to talk about the whole world then I wanted to see big. The motto we had for the play and production from the beginning was too much... It is very much an epic play in the Brechtian sense"[ 69]. Bartlett believes that the large number of characters and scenes in his play is to the credit of his play. This is true; IT gives more 
comprehensiveness and illustrates his idea very well diverting the attention of audience to the dangers of violating Nature. This also keeps the linearity of the plot.

The stage in Earthquakes in London is divided into two parts and has more than one hole. This is very impressive and proper to the passage of time so as the events of the play occurs in far distant and long periods of time. Scenes develop smoothly. Spencer comments:" There are two raised proscenium arch stages for more intimate scenes". Also this division of the stage helps in containing a large number of characters. Bartlett insists that the stage should overflow with scenery and the characters issues seem symptomatic of the time we live in. This helps the audience realize the social essence in this play. Furthermore, it involves audience in the action before them on the stage. Accordingly the audience realize that they are products of society and responsible for making the social conventions that bond them and draw their lives. Accordingly, Man's relation to Nature is confirmed. This stage with its chaos is a shift of the whole Nature with its suffering from people's misuse of.

Although the serious issues discussed in this play, the sense of irony is very clear. It is some sort of black ironies that uncovers the deep sufferings of the characters. The plot is very attractive. The author manipulates time in a very surprising way. The events of the play begin in the 1960s of the last century and last to 2525. Time runs very quickly. This helps in predicting the future of the characters within these rapid and excessive climatic changes. For instance, the play ends with Freya's young children who is in the spectrum of autism"[115]. Also this long period of time requires a long 
play. Due to the length of the play, the author relies on massive props, elements, stories, and characters. So he employs musical scenes, etc. For Broockman" The plot weaves between the stories it portrays at breakneck speed, somehow finding reasons to throw in several musical numbers, scenes, that take place between 1968 and a political burlesque". This helps in baring the claustrophobic atmosphere that wraps both the great city of London, where the main story occurs, represented by the expected earthquakes, hurricanes and tsunamis, and all the characters in the play. This exposes the severe conflict between Man and Nature as commented by Ning Wang as:" human beings are more and more suffering from the punishment inflicted by Nature". Bartlett controlled his stage in a way that reflects this conflict.

\section{Conclusion}

In a nut shell, Earthquakes in London is a play that pays attention to the importance of the climatic changes represented in this play through talking about the apocalyptic earthquakes and global warming that endanger London. This play deals with the issue of the climatic changes within a social and an urban frame. The play tells the story of the troubled relation between the father Robert who works as an environmentalist and his three daughters whose relations with each other are troubled also. So it can be said that the second- wave eco criticism can be studied in the play under study. Bartlett introduces an epic work with a big number of characters. Characters in this play represent different sectors of Londoners; it is very important and suggestive. It shows

(THE ECOLOGICAL FUNCTION...)Dr. Ruwayda Gaber 
how people generally are responsible for the apocalypse of environment. It also shows how people are in a dire need for a healthy environment. Hence, the concept of environmental justice can be studied within Earthquakes in London. As it is mentioned before, characters in this play represent various sectors of Londoners with different careers. Language in this play is attractive. Although it is written in the daily language, it is not a vernacular language. The author makes use of punctuation marks in a way that shows the main idea of the play. For instance, slash (I) is used when a speech starts soon, while dash (-) is used when a speech interrupts the other. However, sometimes language in this play turns into preach or oration in some points; this is a backdrop in the technique of this play, in spite of its well good technique and welldesigned stage. Due to the large number of characters, this play is a scenery play whose author controls stage professionally. Stage is well- used in Earthquakes in London. It is divided into two parts for two reasons: First, to include the big number of characters. Second, to express the different times when the events of the play happen. The events of the play begin in 1968 and ends in 2525. Relying on such a long period of time is significant to show how different generations are directly influenced by the climatic changes of their ancestors. 


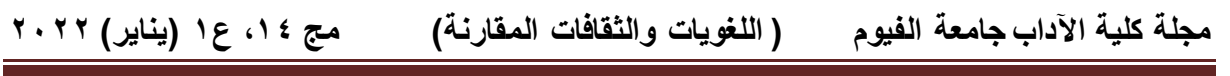

\section{Bibliography}

Amaladass, Anand." Sustinable Development and Religion: Towards an Economic- Eco- Socio- Spirituality". Essays in Ecocriticism. Ed. Nirmal Selvamony etal. OSLE: New Delhi, 2007.

Billignton, Michael." Earthquakes in London". The Guardian. August 5, 2010.

www.theguardian.com/stage/2010/aug/05/earthquakes-in-

london-michael-

billington.

Bratlett, Mike. Earthquakes in London. Methuen: London,2010.

Broockmann, Kerstin. "Earthquakes in London" Rocks@

Steep Theatre'. March 3, 2017. Chicago Stage Standard.

https://www.chicagostagestandard.com/home/2017/3/3/earthqu

akes-in-london-

rocks-steep-theatre.

Bull, Lawrence. The Future of Environmental Criticism: Environmental Crisis and

Literary Imagination. Blackwell Publishing: USA, 2005.

----. The Environmental Imagination: Thoreau, Nature Writing, and the Formation of American Culture Revised Edition. Harvard University Press: USA, 1996.

Carr, Flora." Doctor Foster Writer Mike Bartlett Had to Learn How to be a Good Bully for ITV Workplace Drama Sticks and Stones". Radio Times. December 18, 2019. https://www.radiotimes.com/news/2019-12-18/mike-_ bartlettbullying-sticks-and-stones/.

Glotfelty, Cherll and Harold Fromm. The Ecocriticism Reader: Landmarks in Literary Ecology. The University of Georgia Press: Georgia, 1996. 
Gluhovic Milija, and Jisha Menon. Performing the Secular: Religion, Representation, and Politics. Palgrave Macmillan: England, 2017.

Green, Kevin." Sparking, Not Stirring: A review of Earthquakes in London at Steep Theatre Company". Newcitystage. Jan 24, 2017.https://www.newcitystage.com/2017/01/28/shaking-notstirring-a-review-of- earthquakes-in-london-at-steeptheatre-company.

Hulme, Mike. Why We Disguise About Climate Change. Cambridge Univ. Press: England, 2009.

Kakkoven, Gordana Galic." Theoretical Premises of Ecocriticism". The International Journal of Sustainability in Economics, Social, and Cultural Context. Vol.12. Issue.1. Common Ground Publishing LLC: USA. 2016. P. 14. Jones, Chris.' Earthquakes in London' a very personal play about the whole planet". Chicago Tribune. Jan 29, 2017.https://ww w.chicagotribune.com/entertainment/theater/c t-earthquakes-in-london-ent-0130-20170129-column.html.

Sierz, Aleks." Earthquakes in London, National Theatre". The arts desk. Com. August 4, 2010.

https://theartsdesk.com/theatre/earthquakes-london-nationaltheatre.

Spencer, Charles." Earthquakes in London is a Brillintly Inventive Account of Life, Love, and Performed Unease in Present Day London. Rating”. The Telegraph. August 5, 2010. https://www.telegraph.co.uk/culture/the atre/theatre-revie. 


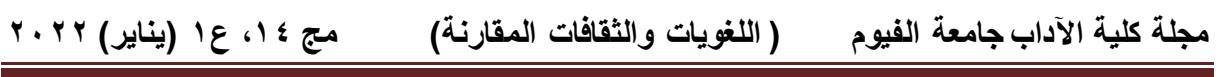

Taylor, Paul." Earthquakes in London, National Theatre:

Cottesloe, London." Independent. Friday 6

August2010.https://www.independent.co.uk/arts-

entertainment/theatre-dance/reviews/earthquakes-in-london-

national-theatre-cottesloe-london-2044606.html.

Wang, Ning." Ecocriticism: Literary Studies in An Age of

Environmental Crisis.". In Interconnections between Human and

Ecosystem Health. Ed. Richard T. Digiulion and Emily Monsson.

Chapman and Hall: London, 1996. 